\title{
Use of Sensitivity Method for the Detection and the Localization of Linear System Defect
}

\author{
Hassene Bedoui ${ }^{1}$, Nasreddine Bouguila ${ }^{1}$ and Kamel Ben Othman ${ }^{2}$ \\ ${ }^{1}$ LARATSI, National Engineering School of Monastir - ENIM, University of Monastir, \\ 19 Rue Ibn El Jazzar, 5019 Monastir, Tunisia \\ ${ }^{2}$ LARA, National Engineering School of Tunis - ENIT, University of Tunis Manar \\ BP 37, le Belvédère, 1002 Tunis, Tunisia
}

\begin{abstract}
The methods of the fault diagnosis and degradations used in the different industrial sectors are various and consider the specifity of the materials forming their industrial processes. For some relatively simple processes, the relations between the causes and their effects are Biunivocal and the diagnosis with reverse reasoning is easy. Contrarily for the complexes processes, the situation is slightly different and is impossible to precede a deductive reasoning. The diagnosis is therefore only possible by using a different and a complementary knowledge. The sensitivity method for the detection and localization of the linear system defects is used in this paper.
\end{abstract}

Keywords: - Sensitivity, linear system, fault, faulty and defect

\section{Introduction}

Fault detection is a very wide field of research. Indeed, in industrial technology fields such as transport of energy [1,2] and aerospace [3], defects must absolutely be detected.

In this paper, we present a diagnosis method based on the sensitivity theory [4]. This method can detect and localize the defects that may exist in a linear system.

Once the model of the faulty linear system is obtained [5-8], the sensitivity matrix of the initial system is computed and the tolerance intervals of all the system are defined, we can detect and localize the faults that affect the system. This method has been applied to second and third order linear systems.

\section{Method Principle}

For a second order system, the localization problem doesn't arise really, since, having two equations with two unknown parameters, we can determine their values and check their appurtenance to tolerance intervals. However, for higher order system this assumption is not guaranteed [9-11].

For a third order system with depending coefficients, the variation of two unknown parameters should verify a system of three equations. This kind of systems not always have solutions, determining of both parameters remains almost impossible. In such this case, we use the sensitivity which enables to determine from the variations of the transfer function coefficient, the parameter causing the fault [5, 12-14], knowing the influence of its variation on these coefficients. The principle of the sensitivity method is described by Figure 1. 


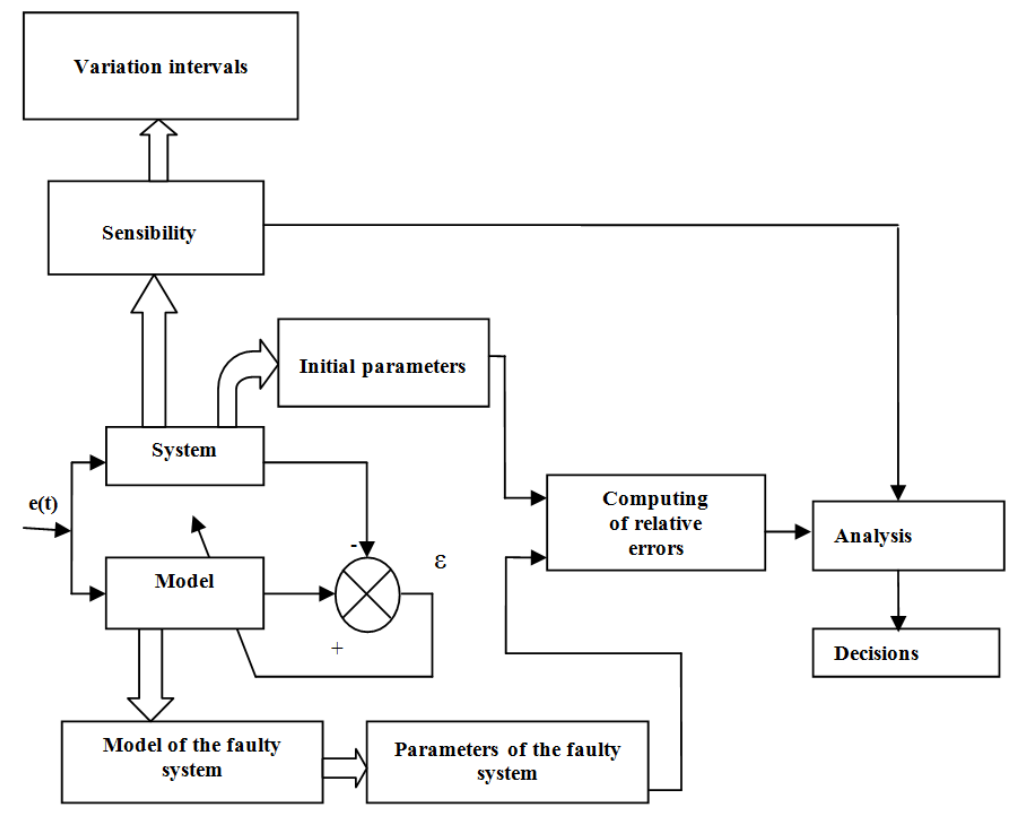

Figure 1. Fault detection and localization using the sensitivity technique

\section{Theory of the Sensitivity of System Performances with Respect to Parameter Variations}

$\mathrm{H}(\mathrm{p}, \mathrm{x})$ the transfer function of a given system depending on a real parameter $x$ which has a nominal value $x_{n}$ and the corresponding transfer function $\mathrm{H}(\mathrm{p}, \mathrm{xn})$ is noted $\mathrm{H}(\mathrm{p})$. In the following, we focus on the variation of the real $\mathrm{x}$ around its nominal value $x_{n}$. We show that $H(p, x)$ is a homographic function of $x$ such as :

$$
H(p, x)=\frac{C(p)+x D(p)}{A(p)+x B(p)}
$$

the coefficients of polynomials $\mathrm{A}(\mathrm{p}), \mathrm{B}(\mathrm{p}), \mathrm{C}(\mathrm{p})$ and $\mathrm{D}(\mathrm{p})$ are real, independent of $x$.

\subsection{Classical Sensitivity}

Assume that $x$ is the only parameter which varies. The classical sensitivity of a transfer function $\mathrm{H}(\mathrm{p}, \mathrm{x})$ with respect to $x$ is:

$$
S_{x}^{H}(p, x)=\frac{d H / H}{d x / x}=\frac{d(\log H)}{d(\log x)}
$$

\subsubsection{Properties}

If $\mathrm{H}(\mathrm{p}, \mathrm{x})=\frac{\mathrm{P}(\mathrm{p}, \mathrm{x})}{\mathrm{Q}(\mathrm{p}, \mathrm{x})}$ we have: 


$$
\mathrm{S}_{\mathrm{x}}^{\mathrm{H}}(\mathrm{p}, \mathrm{x})=\mathrm{x}\left[\frac{1}{\mathrm{P}(\mathrm{p}, \mathrm{x})} \frac{\partial \mathrm{P}}{\partial \mathrm{x}}-\frac{1}{\mathrm{Q}(\mathrm{p}, \mathrm{x})} \frac{\partial \mathrm{Q}}{\partial \mathrm{x}}\right]
$$

Let's consider the frequential study $(\mathrm{p}=\mathrm{j} \omega)$ :

$$
\begin{aligned}
& \log [H(j \omega, x)]=\log |H(j \omega, x)|+j \operatorname{Arg}(H(j \omega, x)) \\
& S_{x}^{H}(p, x)=\frac{d(\log H)}{d(\log x)} \\
& =x \frac{d[\log |H(j \omega, x)|]}{d x}+j x \frac{d[\operatorname{Arg}(H(j \omega, x))]}{d x}
\end{aligned}
$$

We deduce the following equalities:

$$
\begin{gathered}
\operatorname{Re}\left(S_{x}^{H}\right)=x \frac{d[\log |H|]}{d x}=\frac{x}{d x} \frac{d|H|}{|H|} \\
\operatorname{Im}\left(S_{x}^{H}\right)=x \frac{d(\operatorname{Arg}(H))}{d x}
\end{gathered}
$$

For a small variation $\delta \mathrm{x}$ of $\mathrm{x}$ we have then:

$$
\frac{\delta|\mathrm{H}|}{|\mathrm{H}|}=\operatorname{Re}\left(\mathrm{S}_{\mathrm{x}}^{\mathrm{H}}\right) \frac{\delta \mathrm{x}}{\mathrm{x}}
$$

and

$$
\delta(\operatorname{Arg}(\mathrm{H}))=\operatorname{Im}\left(\mathrm{S}_{\mathrm{x}}^{\mathrm{H}}\right) \frac{\delta \mathrm{x}}{\mathrm{x}}
$$




\subsection{Generalization}

When $\mathrm{H}(\mathrm{p})$ depends of many parameters $\mathrm{x}_{1}, \mathrm{x}_{2}, \ldots, \mathrm{x}_{\mathrm{n}}$, we have:

$$
\begin{aligned}
& \mathrm{dH}= \frac{\partial \mathrm{H}}{\partial \mathrm{x}_{1}}\left(\mathrm{p}, \mathrm{x}_{1}, \mathrm{x}_{2}, \ldots, \mathrm{x}_{\mathrm{n}}\right) \mathrm{dx_{1 }}+\frac{\partial \mathrm{H}}{\partial \mathrm{x}_{2}} \mathrm{dx}_{2}+\ldots \\
&+\frac{\partial \mathrm{H}}{\partial \mathrm{x}_{\mathrm{n}}} \mathrm{dx}_{\mathrm{n}} \\
& \frac{\mathrm{dH}}{\mathrm{H}}=\mathrm{d}(\operatorname{LogH})=\sum_{\mathrm{i}=1}^{\mathrm{n}} \mathrm{S}_{\mathrm{xi}}^{\mathrm{H}} \frac{\mathrm{dx}_{\mathrm{i}}}{\mathrm{x}_{\mathrm{i}}}
\end{aligned}
$$

We define the vector $S^{H}$ as:

$$
S_{x i}^{H}=\frac{\partial(\log H)}{\partial\left(\log x_{i}\right)}
$$

and the column vector $\Delta$ the term of which $\operatorname{are} \mathrm{d}\left(\log \mathrm{x}_{\mathrm{i}}\right)$, we have:

$$
\frac{\mathrm{dH}}{\mathrm{H}}=\left(\mathrm{S}^{\mathrm{H}}\right)^{\mathrm{T}} \cdot \Delta
$$

Where $\left(S^{\mathrm{H}}\right)^{\mathrm{T}}$ it the transpose of $\mathrm{S}^{\mathrm{H}}$.

\subsection{Sensitivity of poles and zeros of $H(p, x)$ with respect to $x$}

\subsubsection{Case of one root (pole or zero)}

Let $\mathrm{p}_{\mathrm{j}}$ a pole of a zero of a transfer function $\mathrm{H}(\mathrm{p}, \mathrm{x})$. The variation of $\mathrm{x}$ to $\mathrm{x}+\mathrm{dx}$ transforms the pole $\mathrm{p}_{\mathrm{j}}$ to $\mathrm{p}_{\mathrm{j}}+\mathrm{d} \mathrm{p}_{\mathrm{j}}$. The sensitivity of $\mathrm{p}_{\mathrm{j}}$ with respect to $x$ is given by:

$$
S_{x}^{p_{j}}=\frac{d p_{j}}{d x / x}
$$

Since the performances of any system depend the position of its poles and zeros (roots), the classical sensitivity is therefore related to the root sensitivity.

Let study the case of poles which are assumed to be all simple. A similar reasoning can be applied in the case of the zeros. 
Let $\mathrm{Q}(\mathrm{p}, \mathrm{x})$ the denominator of $\mathrm{H}(\mathrm{p}, \mathrm{x})$; it can be written as:

$$
\mathrm{Q}(\mathrm{p}, \mathrm{x})=\mathrm{A}(\mathrm{p})+\mathrm{x} \mathrm{B}(\mathrm{p})
$$

Let $\mathrm{p}_{\mathrm{j}}$ a root of $\mathrm{Q}(\mathrm{p}, \mathrm{x})$, we have:

$$
\mathrm{A}\left(\mathrm{p}_{\mathrm{j}}\right)+\mathrm{x} \mathrm{B}\left(\mathrm{p}_{\mathrm{j}}\right)=0
$$

For the variation of $x$ to $x+d x$, the pole $p_{j}$ moves to $t p_{j}^{\prime}=p_{j}+d p_{j}$ and the relation (15) become:

$$
A\left(p_{j}^{\prime}\right)+(x+d x) B\left(p_{j}^{\prime}\right)=0
$$

If $F(p, x)=\frac{x B(p)}{Q(p, x)}$, the poles of $F(p, x)$ are the roots of $Q(p, x)$ and we have:

$$
1+\frac{d x}{x} F\left(p_{j}^{\prime}, x\right)=0
$$

Then $\mathrm{F}(\mathrm{p}, \mathrm{x})$ becomes:

$$
\mathrm{F}(\mathrm{p}, \mathrm{x})=\sum_{\mathrm{i}} \frac{\mathrm{K}_{\mathrm{i}}}{\mathrm{p}+\mathrm{p}_{\mathrm{i}}}
$$

Where $K_{i}$ is the residual of $F(p, x)$ relatively to the pole $p_{i}$. We have:

$$
1+\frac{d x}{x}\left[\sum_{i} \frac{\mathrm{K}_{\mathrm{i}}}{\mathrm{p}_{\mathrm{j}}^{\prime}+\mathrm{p}_{\mathrm{i}}}\right]=0
$$

By neglecting the terms which goes to zero with dx, the relation (19) is written

$$
1+\frac{d x}{x}\left[\frac{K_{j}}{p_{j}^{\prime}+p_{j}}\right]=1+\frac{d x}{x}\left[\frac{K_{j}}{d p_{j}}\right]
$$

Where

$$
S_{x}^{p_{j}}=\frac{x_{d p}}{d x}=-K_{j}
$$

If the numerator of $\mathrm{H}(\mathrm{p}, \mathrm{x})$ is $\mathrm{P}(\mathrm{p}, \mathrm{x})=\mathrm{C}(\mathrm{p})+\mathrm{x} \mathrm{D}(\mathrm{p})$ and if $\mathrm{z}_{\mathrm{i}}$ is a simple root of $\mathrm{P}(\mathrm{p}, \mathrm{x})$ we have:

$$
\mathrm{S}_{\mathrm{x}}^{\mathrm{z}_{\mathrm{i}}}=-\mathrm{K}_{\mathrm{i}}
$$

Where $K_{i}$ is the residual relative to $z_{i}$. 
Since $\mathrm{p}_{\mathrm{j}}$ et $\mathrm{z}_{\mathrm{i}}$ are assumed to be simple roots, we have:

$$
\mathrm{K}_{\mathrm{j}}=\operatorname{résidu}\left[\frac{\mathrm{x} B(\mathrm{p})}{\mathrm{Q}(\mathrm{p}, \mathrm{x})}\right]_{\mathrm{p}=\mathrm{p}_{\mathrm{j}}}=\frac{\mathrm{x} \mathrm{B}\left(\mathrm{p}_{\mathrm{j}}\right)}{\mathrm{Q}^{\prime}\left(\mathrm{x}, \mathrm{p}_{\mathrm{j}}\right)}
$$

and

$$
\mathrm{K}_{\mathrm{i}}=\operatorname{résidu}\left[\frac{\mathrm{x} \mathrm{D}(\mathrm{p})}{\mathrm{p}(\mathrm{p}, \mathrm{x})}\right]_{\mathrm{p}=\mathrm{z}_{\mathrm{i}}}=\frac{\mathrm{x} \mathrm{D}\left(\mathrm{z}_{\mathrm{i}}\right)}{\mathrm{P}^{\prime}\left(\mathrm{x}, \mathrm{z}_{\mathrm{i}}\right)}
$$

In the following we formulate the classical sensitivity in term of root sensitivity:

$$
\mathrm{S}_{\mathrm{x}}^{\mathrm{H}}(\mathrm{p}, \mathrm{x})=\mathrm{x}\left[\frac{\mathrm{P}^{\prime}}{\mathrm{P}}-\frac{\mathrm{Q}^{\prime}}{\mathrm{Q}}\right]
$$

Since we have $\frac{\mathrm{P}^{\prime}}{\mathrm{P}}=\frac{\mathrm{D}(\mathrm{p})}{\mathrm{P}(\mathrm{p}, \mathrm{x})} \quad$ and $\quad \frac{\mathrm{Q}^{\prime}}{\mathrm{Q}}=\frac{\mathrm{B}(\mathrm{p})}{\mathrm{Q}(\mathrm{p}, \mathrm{x})}$

then

$$
\begin{aligned}
S_{x}^{H}(p, x) & =G(p, x)-F(p, x) \\
& =\sum_{j} \frac{S_{x}^{p_{j}}}{p_{-} p_{j}}-\sum_{i} \frac{S_{x}^{z_{i}}}{p_{-} z_{i}}
\end{aligned}
$$

\subsection{Generalization of sensitivity matrix}

Let $\mathrm{P}(\mathrm{p})$ a polynomial with real coefficients and simple roots:

$$
\mathrm{P}(\mathrm{p})=\sum_{\mathrm{i}=0}^{\mathrm{n}} \mathrm{a}_{\mathrm{i}} \mathrm{p}^{\mathrm{i}}
$$

Without loss of generality we assume that $a_{n}=1$; the coefficients $a_{i}$ are function of $\mathrm{m}$ parameters $\mathrm{x}_{1}, \mathrm{x}_{2}, \ldots, \mathrm{x}_{\mathrm{m}}$ and $\mathrm{a}_{\mathrm{i}}=\mathrm{f}_{\mathrm{i}}\left(\mathrm{x}_{1}, \mathrm{x}_{2}, \ldots, \mathrm{x}_{\mathrm{m}}\right)$.

Let changing $x_{j}$ to $x_{j}+d x_{j}(j=1, \ldots, m)$ and assume that $d a_{i}$ the variation of $a_{i},(i=1, \ldots, n-$ 1). If we define $\Delta \mathrm{a}$ the column vector containing the variations $\mathrm{da}_{\mathrm{i}}$ and $\Delta \mathrm{x}$ the column vector containing the variations $\mathrm{dx}_{\mathrm{j}}$, we can write:

$$
\Delta \mathrm{a}=\mathrm{F} . \Delta \mathrm{x}
$$

Where $F$ is a $(n * m)$-dimensional matrix the components of which $f_{i j}$ are given by $f_{i j}=\frac{\partial f_{i}}{\partial x_{j}}$. 
$\mathrm{P}(\mathrm{p})$ can be written as:

$$
P(p)=\prod_{i=1}^{q}\left(p^{2}+b_{2 i-1} p+b_{2 i}\right) \prod_{i=2 q+1}^{n}\left(p+b_{i}\right)
$$

The polynomials $\left(p^{2}+b_{2 i-1} p+b_{2 i}\right)$ have complex roots and those of the form $\left(p+b_{i}\right)$ have real roots. The variation of $b_{j}$ influences the variations of the roots more than those of the $\mathrm{a}_{\mathrm{i}}$. If $\Delta \mathrm{b}$ is column vector with components $\mathrm{db}_{\mathrm{j}}$, we have

$$
\Delta \mathrm{a}=\mathrm{D} . \Delta \mathrm{b}
$$

Where $D$ is a n-dimensional matrix, the coefficients of which are $d_{i j}=\frac{\partial a_{i}}{\partial b_{j}}$. If $D$ is a regular matrix we can write:

$$
\Delta \mathrm{b}=\mathrm{D}^{-1} . \mathrm{F} \cdot \Delta \mathrm{x}
$$

Let $\mathrm{B}$ a diagonal matrix with $\mathrm{B}_{\mathrm{ii}}=\mathrm{b}_{\mathrm{i}}$ and $\Delta \mathrm{b}$ a column vector $\Delta \mathrm{B}_{\mathrm{i}}=\frac{\mathrm{db}_{\mathrm{i}}}{\mathrm{b}_{\mathrm{i}}}$, we have:

$$
\Delta \mathrm{b}=\mathrm{B} \cdot \Delta \mathrm{B}
$$

Similarly we can write (with $\Delta \mathrm{x}_{\mathrm{j}}=\mathrm{dx}_{\mathrm{j}} / \mathrm{x}_{\mathrm{j}}$ and $\mathrm{X}_{\mathrm{jj}}=\mathrm{x}_{\mathrm{j}}$ ):

$$
\Delta \mathrm{x}=\mathrm{X} \cdot \Delta \mathrm{X}
$$

The relations (30) - (32) leads to:

$$
\Delta \mathrm{B}=\mathrm{B}^{-1} \cdot \mathrm{D}^{-1} \cdot \mathrm{F} \cdot \mathrm{X} \cdot \Delta \mathrm{X}
$$

We define the sensitivity matrix $\mathrm{S}$ as:

$$
\mathrm{S}=\mathrm{B}^{-1} \cdot \mathrm{D}^{-1} \cdot \mathrm{F} \cdot \mathrm{X}
$$

With

$$
\mathrm{S}_{\mathrm{ij}}=\frac{\mathrm{db}_{\mathrm{i}} / \mathrm{b}_{\mathrm{i}}}{\mathrm{dx} \mathrm{x}_{\mathrm{j}} / \mathrm{x}_{\mathrm{j}}}
$$

\section{Detection and Localization of a Linear System using Sensitivity}

In this section we intend to determine, the safe functioning domains of a second order and third order linear systems using the tolerance intervals relative to the parameters of then transfer functions.

The starting from transfer functions describing defect system we determine the fault causes using the sensitivity approach. 


\subsection{Determination of the safe functioning domain}

\subsection{Case of a second order system}

Let the following second order system given by its transfer function:

$$
\mathrm{H}_{2}(\mathrm{p})=\frac{1}{\frac{1}{\omega_{0}^{2}} \mathrm{p}^{2}+\frac{2 \xi}{\omega_{0}} \mathrm{p}+1}
$$

Where $\omega_{0}$ represents the natural pulsation and $\xi$ is the damping factor.

The aim of this section is to determine a domain in which we can ensure a normal functioning of our process. $\omega_{0}=10$ and $\xi=0.4$. The safe functioning is defined by the tolerance intervals relative to $\omega_{0}$ and $\xi$ as:

$$
\Delta \omega_{0}=\left[\omega_{0}-10 \% ; \omega_{0}+10 \%\right] \text { and } \Delta \xi=[\xi-10 \% ; \xi+10 \%]
$$

These intervals should be respected to determine validity domain of the system step response.

This is done by considering all the variations of the parameters $\left(\omega_{0}\right.$ and $\left.\xi\right)$ as summarized in Table 1.

Table 1. Validity domain by considering the variations of the parameters $\omega_{0}$ and $\xi$

\begin{tabular}{|c|c|c|c|}
\hline Case $^{\circ}$ & Variation of $\boldsymbol{\omega}_{\mathbf{0}}$ & Variation of $\boldsymbol{\xi}$ & Expression of H(p) \\
\hline $\mathbf{1}$ & $-10 \%$ & $-10 \%$ & $\frac{1}{0.0123 \mathrm{p}^{2}+0.08 \mathrm{p}+1}$ \\
\hline $\mathbf{2}$ & $-10 \%$ & $0 \%$ & $\frac{1}{0.0123 \mathrm{p}^{2}+0.088 \mathrm{p}+1}$ \\
\hline $\mathbf{3}$ & $-10 \%$ & $10 \%$ & $\frac{1}{0.0123 \mathrm{p}^{2}+0.097 \mathrm{p}+1}$ \\
\hline $\mathbf{4}$ & $0 \%$ & $-10 \%$ & $\frac{1}{0.01 \mathrm{p}^{2}+0.072 \mathrm{p}+1}$ \\
\hline $\mathbf{5}$ & $0 \%$ & $10 \%$ & $\frac{1}{0.01 \mathrm{p}^{2}+0.088 \mathrm{p}+1}$ \\
\hline $\mathbf{6}$ & $10 \%$ & $-10 \%$ & $\frac{1}{0.0082 \mathrm{p}^{2}+0.065 \mathrm{p}+1}$ \\
\hline $\mathbf{7}$ & $10 \%$ & $0 \%$ & $\frac{1}{0.0082 \mathrm{p}^{2}+0.072 \mathrm{p}+1}$ \\
\hline $\mathbf{8}$ & $10 \%$ & $10 \%$ & $\frac{1}{0.0082 \mathrm{p}^{2}+0.08 \mathrm{p}+1}$ \\
\hline
\end{tabular}


The Figure 2 illustrates the functioning domain when a unit step is chose as system input.

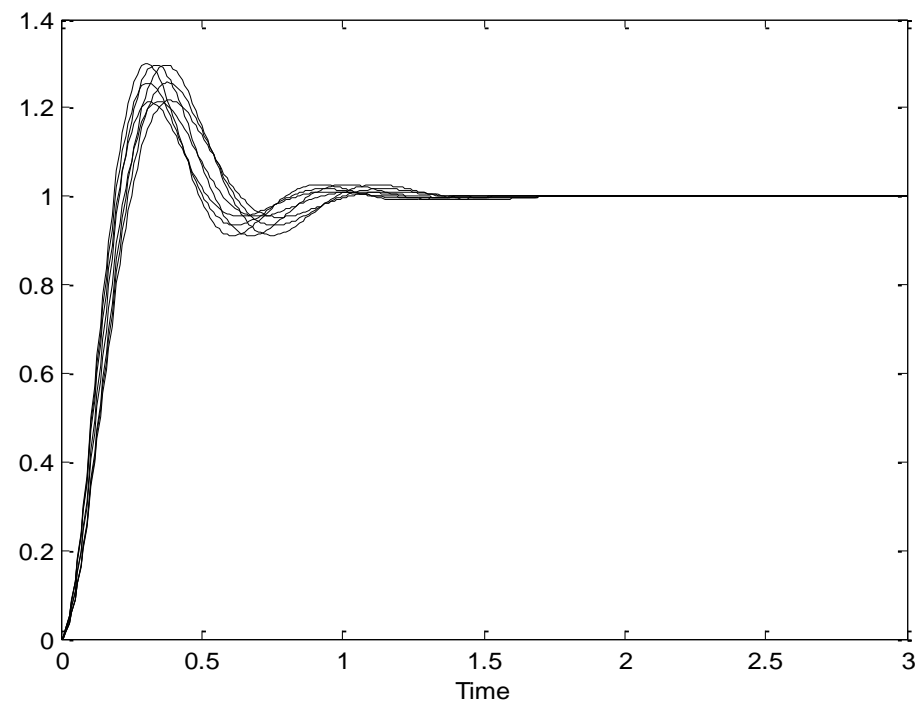

Figure 2. Safe functioning domain of a second order system

\subsubsection{Third order system}

Let consider a third order system given by transfer function:

$$
\mathrm{H}_{3}(\mathrm{p})=\frac{1}{\mathrm{p}^{3}+\left(5 \mathrm{x}_{1}-\mathrm{x}_{2}\right) \mathrm{p}^{2}+\left(\mathrm{x}_{1} \mathrm{x}_{2}+2\right) \mathrm{p}+\mathrm{x}_{1} \mathrm{x}_{2}}
$$

Where $\mathrm{x}_{1}$ and $\mathrm{x}_{2}$ define the system parameters

$$
\text { Let } \mathrm{x}_{1}=1 \text { and } \mathrm{x}_{2}=2 \text {. }
$$

The tolerance interval which guarantee a safe functioning are:

$$
\Delta \mathrm{x}_{1}=\left[\mathrm{x}_{1}-10 \% ; \mathrm{x}_{1}+10 \%\right]
$$

and

$$
\Delta \mathrm{x}_{2}=\left[\mathrm{x}_{2}-10 \% ; \mathrm{x}_{2}+10 \%\right]
$$

The different cases of both parameter variations are given by Table 2, which the functioning domain is given by Figure 3 .

Table 2. The different cases of the parameter $x 1$ and $x 2$ variations

\begin{tabular}{|c|c|c|c|}
\hline Case $^{\circ}$ & Variation of $\mathbf{x}_{\mathbf{1}}$ & Variation of $\mathbf{x}_{\mathbf{2}}$ & Expression of $\mathbf{H}(\mathbf{p})$ \\
\hline $\mathbf{1}$ & $-10 \%$ & $-10 \%$ & $\frac{1}{\mathrm{p}^{3}+2.7 \mathrm{p}^{2}+3.62 \mathrm{p}+1.62}$ \\
\hline $\mathbf{2}$ & $-10 \%$ & $0 \%$ & $\frac{1}{\mathrm{p}^{3}+2.5 \mathrm{p}^{2}+3.8 \mathrm{p}+1.8}$ \\
\hline
\end{tabular}


International Journal of Control and Automation Vol.7, No.5 (2014)

\begin{tabular}{|c|c|c|c|}
\hline $\mathbf{3}$ & $-10 \%$ & $10 \%$ & $\frac{1}{\mathrm{p}^{3}+2.3 \mathrm{p}^{2}+3.98 \mathrm{p}+1.98}$ \\
\hline $\mathbf{4}$ & $0 \%$ & $-10 \%$ & $\frac{1}{\mathrm{p}^{3}+3.2 \mathrm{p}^{2}+3.8 \mathrm{p}+1.8}$ \\
\hline $\mathbf{5}$ & $0 \%$ & $10 \%$ & $\frac{1}{\mathrm{p}^{3}+2.8 \mathrm{p}^{2}+4.2 \mathrm{p}+2.2}$ \\
\hline $\mathbf{6}$ & $10 \%$ & $-10 \%$ & $\frac{1}{\mathrm{p}^{3}+3.7 \mathrm{p}^{2}+3.98 \mathrm{p}+1.98}$ \\
\hline $\mathbf{7}$ & $10 \%$ & $0 \%$ & $\frac{1}{\mathrm{p}^{3}+3.5 \mathrm{p}^{2}+4.2 \mathrm{p}+2.2}$ \\
\hline $\mathbf{8}$ & $10 \%$ & $10 \%$ & $\frac{1}{\mathrm{p}^{3}+3.3 \mathrm{p}^{2}+4.42 \mathrm{p}+2.42}$ \\
\hline
\end{tabular}

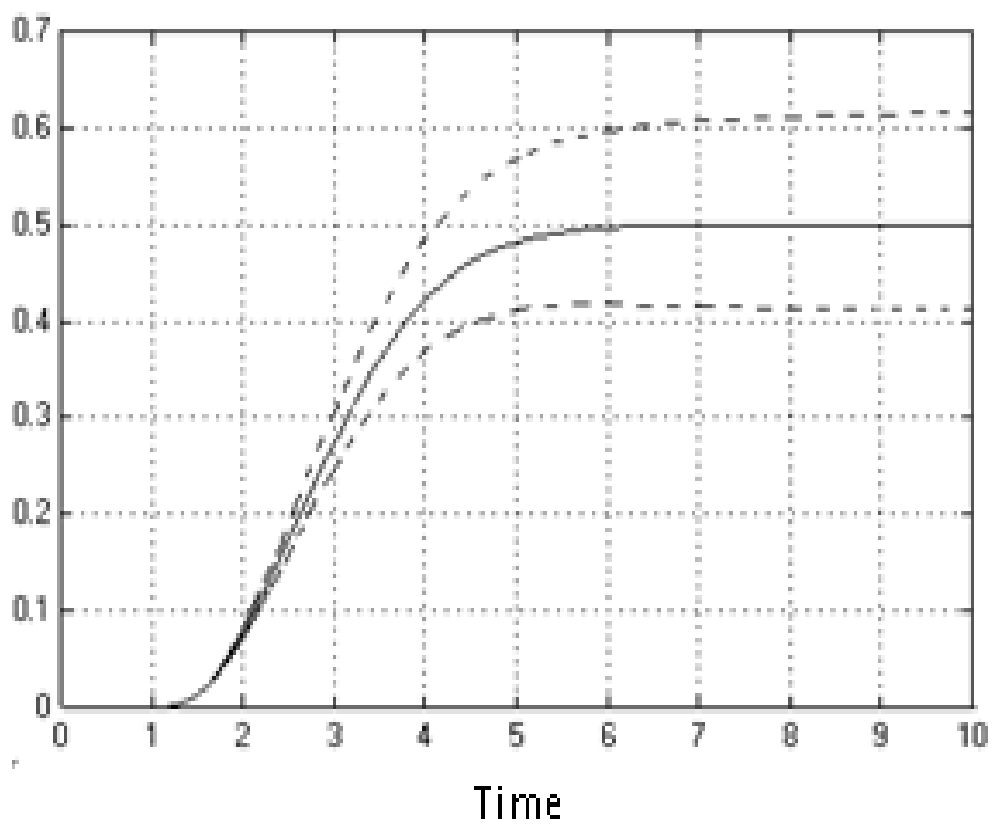

Figure 3. Domain of safe functioning of a third order system

\subsection{Determination of the fault causes}

We propose to determine the parameter which causes the fault by using the sensibility notion detailed previously. 


\subsubsection{Second order system}

The Laplace transform of a second order step response is:

$$
\mathrm{S}(\mathrm{p})=\frac{1}{\frac{1}{\omega_{0}^{2}} \mathrm{p}^{3}+\frac{2 \xi}{\omega_{0}} \mathrm{p}^{2}+\mathrm{p}}
$$

and its transfer function is:

$$
\mathrm{H}(\mathrm{p})=\frac{1}{\frac{1}{\omega_{0}^{2}} \mathrm{p}^{2}+\frac{2 \xi}{\omega_{0}} \mathrm{p}+1}
$$

Let's determine the sensibility matrix:

Consider the polynomial $\mathrm{Q}(\mathrm{p})$ defined as:

$$
\mathrm{Q}(\mathrm{p})=\frac{1}{\omega_{0}^{2}} \mathrm{p}^{2}+\frac{2 \xi}{\omega_{0}} \mathrm{p}+1
$$

Since the sensibility considers essentially, the pole variation we consider the polynomial $\mathrm{P}(\mathrm{p})$ which has the same roots as $\mathrm{Q}(\mathrm{p})$ given by:

$$
\mathrm{P}(\mathrm{p})=\mathrm{p}^{2}+2 \xi \omega_{0} \mathrm{p}+\omega_{0}^{2}
$$

Let

$$
\omega_{0}=\mathrm{x}_{1}=10 \mathrm{rad} . \mathrm{s}^{-1} \quad \text { and } \quad \xi=\mathrm{x}_{2}=0.4
$$

Which yields:

$$
P(p)=p^{2}+a_{1} p+a_{0}=p^{2}+8 p+100
$$

with

$$
\mathrm{a}_{0}=\mathrm{x}_{1}^{2} \quad \text { et } \quad \mathrm{a}_{1}=2 \mathrm{x}_{1} \mathrm{x}_{2}
$$

The matrix $F$, the components of which are $f_{i j}=\frac{\partial a_{i}}{\partial x_{j}}$, is :

$$
F=\left[\begin{array}{cc}
20 & 0 \\
0.8 & 20
\end{array}\right]
$$

The polynomial $\mathrm{P}(\mathrm{p})$ can be written as:

$P(p)=p^{2}+b_{1} p+b_{2}$

The matrix D with $d_{i j}=\frac{\partial a_{i}}{\partial b_{j}}$ is:

$$
\mathrm{D}=\left[\begin{array}{ll}
0 & 1 \\
1 & 0
\end{array}\right]
$$


The diagonal matrices $\mathrm{B}$ and $\mathrm{X}$ such as $\mathrm{B}_{\mathrm{ii}}=\mathrm{b}_{\mathrm{i}}$ and $\mathrm{X}_{\mathrm{ii}}=\mathrm{x}_{\mathrm{i}}$ are:

$$
\mathrm{B}=\left[\begin{array}{cc}
8 & 0 \\
0 & 100
\end{array}\right] \quad \mathrm{X}=\left[\begin{array}{cc}
10 & 0 \\
0 & 0.4
\end{array}\right]
$$

and the sensibility matrix is defined as:

$$
\mathrm{S}=\mathrm{B}^{-1} \cdot \mathrm{D}^{-1} \cdot \mathrm{F} \cdot \mathrm{X}=\left[\begin{array}{ll}
1 & 1 \\
2 & 0
\end{array}\right]
$$

Which means $\left[\begin{array}{l}\Delta \mathrm{B}_{1} \\ \Delta \mathrm{B}_{2}\end{array}\right]=\left[\begin{array}{ll}1 & 1 \\ 2 & 0\end{array}\right] \cdot\left[\begin{array}{l}\Delta \mathrm{X}_{1} \\ \Delta \mathrm{X}_{2}\end{array}\right]$

Based on this result we can state the following:

○ A $1 \%$ variation on $\omega_{0}\left(\frac{\delta \omega_{0}}{\omega_{0}}=0.01\right)$ implies:

$$
\begin{aligned}
& \text { - variation of } \mathrm{b}_{1} \text { of } 1 \%\left(\frac{\delta \mathrm{b}_{1}}{\mathrm{~b}_{1}}=0.01\right) \\
& \text { - variation of } \mathrm{b}_{2} \text { of } 2 \%\left(\frac{\delta \mathrm{b}_{2}}{\mathrm{~b}_{2}}=0.02\right) .
\end{aligned}
$$

- A $1 \%$ variation on $\xi$ implies a $1 \%$ variation on $b_{1}$ but no variation on $b_{2}$.

Therefore since the tolerance intervals are:

$$
\Delta \omega_{0}=\left[\omega_{0}-10 \% ; \omega_{0}+10 \%\right]
$$

and

$$
\Delta \xi=[\xi-10 \% ; \xi+10 \%]
$$

and since the system is faulty (the output $s(t)$ is outside the functioning domain) we can presume that:

- A value of $b_{1}$ outside the interval $\left[b_{01}-10 \%, b_{01}+10 \%\right]$ and a value $b_{2}$ outside the interval $\left[b_{02}-20 \%, b_{02}+20 \%\right]$ imply that the faulty is due to $\omega_{0}$.

$\circ$ A value of $b_{1}$ outside the interval $\left[b_{01}-10 \%, b_{01}+10 \%\right]$ and et de $b_{2} \neq b_{02}$ means that the faulty results from $\xi$.

Where $b_{01}$ and $b_{02}$ are system coefficient before the fault.

\section{Example 1}

Let the second order transfer function $\mathrm{H}(\mathrm{p})=\frac{1}{0.009 \mathrm{p}^{2}+0.09 \mathrm{p}+1}$ its step response doesn't belong to safe functioning domain indicted by 4.2.1. We propose to determine the cause of its fault. 
The polynomial $\mathrm{P}(\mathrm{p})$ obtained from $\mathrm{H}(\mathrm{p})$ is:

$\mathrm{P}(\mathrm{p})=\mathrm{p}^{2}+10 \mathrm{p}+111.11 \mathrm{~b}_{2}$

The non-faulty system transfer function is:

$\mathrm{H}_{0}(\mathrm{p})=\frac{1}{0.01 \mathrm{p}^{2}+0.08 \mathrm{p}+1}$

Which mean $b_{01}=8$ and $b_{02}=100$

Therefore $b_{1}=10=b_{01}+25 \%$

and

$$
\mathrm{b}_{2}=\mathrm{b}_{02}+11.11 \%
$$

We can conclude that the fault is due to $\omega_{0}$.

\subsubsection{Third order system}

The transfer function of our third order system is:

$$
S(p)=\frac{1}{p^{4}+\left(5 x_{1}-x_{2}\right) p^{3}+\left(x_{1} x_{2}+2\right) p^{2}+x_{1} x_{2} p}
$$

and the corresponding step response Laplace transform is :

$$
\mathrm{H}(\mathrm{p})=\frac{1}{\mathrm{p}^{3}+\left(5 \mathrm{x}_{1}-\mathrm{x}_{2}\right) \mathrm{p}^{2}+\left(\mathrm{x}_{1} \mathrm{x}_{2}+2\right) \mathrm{p}+\mathrm{x}_{1} \mathrm{x}_{2}}
$$

and the polynomial $\mathrm{P}(\mathrm{p})$ is:

$$
\mathrm{P}(\mathrm{p})=\mathrm{p}^{3}+\left(5 \mathrm{x}_{1}-\mathrm{x}_{2}\right) \mathrm{p}^{2}+\left(\mathrm{x}_{1} \mathrm{x}_{2}+2\right) \mathrm{p}+\mathrm{x}_{1} \mathrm{x}_{2}
$$

with $\quad \mathrm{x}_{1}=1$ and $\mathrm{x}_{2}=2$

The matrix F is: $\quad F=\left[\begin{array}{cc}2 & 1 \\ 2 & 1 \\ 5 & -1\end{array}\right]$

$\mathrm{P}(\mathrm{p})=\mathrm{p}^{3}+3 \mathrm{p}^{2}+4 \mathrm{p}+2$

$$
=(\mathrm{p}+1)\left(\mathrm{p}^{2}+2 \mathrm{p}+2\right)
$$

$\left[\begin{array}{l}\mathrm{da}_{0} \\ \mathrm{da}_{1} \\ \mathrm{da}_{2}\end{array}\right]=\left[\begin{array}{ccc}0 & \mathrm{~b}_{3} & \mathrm{~b}_{2} \\ \mathrm{~b}_{3} & 1 & \mathrm{~b}_{1} \\ 1 & 0 & 1\end{array}\right] \cdot\left[\begin{array}{l}\mathrm{db}_{1} \\ \mathrm{db}_{2} \\ \mathrm{db}_{3}\end{array}\right]=\Delta \mathrm{a}=\mathrm{D} \cdot \Delta \mathrm{b}$

$\mathrm{b}_{1}=2, \mathrm{~b}_{2}=2$ et $\mathrm{b}_{3}=1$

Then $\mathrm{D}=\left[\begin{array}{lll}0 & 1 & 2 \\ 1 & 1 & 2 \\ 1 & 0 & 1\end{array}\right], \mathrm{D}^{-1}=-\left[\begin{array}{ccc}1 & -1 & 0 \\ 1 & -2 & 2 \\ -1 & 1 & -1\end{array}\right]$, 


$$
\mathrm{B}=\left[\begin{array}{lll}
2 & 0 & 0 \\
0 & 2 & 0 \\
0 & 0 & 1
\end{array}\right] \text { and } \mathrm{X}=\left[\begin{array}{ll}
1 & 0 \\
0 & 2
\end{array}\right]
$$

By taking $\mathrm{db}_{\mathrm{i}}=\delta \mathrm{b}_{\mathrm{i}}$ and $\mathrm{dx} \mathrm{x}_{\mathrm{j}}=\delta \mathrm{x}_{\mathrm{j}}$, we have:

$$
\left[\begin{array}{l}
\Delta \mathrm{B}_{1} \\
\Delta \mathrm{B}_{2} \\
\Delta \mathrm{B}_{3}
\end{array}\right]=\left[\begin{array}{cc}
0 & 0 \\
-4 & 3 \\
5 & -2
\end{array}\right] \cdot\left[\begin{array}{l}
\Delta \mathrm{X}_{1} \\
\\
\Delta \mathrm{X}_{2}
\end{array}\right]
$$

Based on this result we can presume that:

○ $1 \%$ variation on $\mathrm{x}_{1}$ implies a $-4 \%$ variation on $\mathrm{b}_{1}$ and $5 \%$.variation on $\mathrm{b}_{3}$.

- $1 \%$ variation on $\mathrm{x}_{2}$ leads to $3 \%$ variation on $\mathrm{b}_{2}$ and $2 \%$.variation on $\mathrm{b}_{3}$.

Therefore, since the tolerance intervals are $\Delta \mathrm{x}_{1}=\left[\mathrm{x}_{1}-10 \% ; \mathrm{x}_{1}+10 \%\right]$ and $\Delta \mathrm{x}_{2}=\left[\mathrm{x}_{2}-10 \% ; \mathrm{x}_{2}+10 \%\right]$ and since the system is faulty, we can conclude that:

$\circ$ A value of $b_{2}$ outside the interval $\left[b_{02}-40 \%, b_{02}+40 \%\right]$ and a value of $b_{3}$ outside the interval $\left[\mathrm{b}_{03}-50 \%, \mathrm{~b}_{03}+50 \%\right]$ means that the fault results from $\mathrm{x}_{1}$

○ A value of $b_{2}$ outside the interval $\left[b_{02}-30 \%, b_{02}+30 \%\right]$ and a value of $b_{3}$ outside the interval $\left[b_{03}-20 \%, b_{03}+20 \%\right]$ implies that the fault results from means that the fault results from $\mathrm{x}_{2}$.

where $b_{02}$ and $b_{03}$ are the system coefficients before the fault.

\section{Example 2}

The comparison of the step reponse of the transfer function $\mathrm{H}(\mathrm{p})=\frac{1}{\mathrm{p}^{3}+3.4 \mathrm{p}^{2}+4.1 \mathrm{p}+1.82}$ with that of the domain given by figure 3 confirm the fault existence. We propose to determine the cause leading to this fault.

From the transfer $\mathrm{H}(\mathrm{p})$, the polynomial $\mathrm{P}(\mathrm{p})$ is:

$$
\begin{aligned}
\mathrm{P}(\mathrm{p}) & =\left(\mathrm{p}+\mathrm{b}_{3}\right)\left(\mathrm{p}^{2}+\mathrm{b}_{1} \mathrm{p}+\mathrm{b}_{2}\right) \\
& =(\mathrm{p}+1.4)\left(\mathrm{p}^{2}+2 \mathrm{p}+1.3\right)
\end{aligned}
$$

Or the safe system is given by the transfer function:

$$
H(p)=\frac{1}{p^{3}+3 p^{2}+4 p+2}
$$

Which means $b_{01}=2, b_{02}=2$ and $b_{03}=1$ and which assume that $b_{1}=b_{01}$, $\mathrm{b}_{2}=\mathrm{b}_{02}+40 \%$ and $\mathrm{b}_{3}=\mathrm{b}_{03}-35 \%$. 
Referring to previous results we can affirm that the fault is due to $\mathrm{x}_{2}$.

\subsection{Graphical determination of fault causes}

Assume that the response of the second order system is not completely in the domain as described by Figure 2. The purpose is to seek which of parameter $\omega_{0}$ and $\xi$ is the cause of the abnormal functioning of the system. We remind that the step response of an oscillating second order system is:

$$
\mathrm{s}(\mathrm{t})=1-\mathrm{e}^{-\xi \omega_{0} \mathrm{t}} \cos \left(\omega_{0} \cdot \sqrt{1-\xi^{2}} \cdot \mathrm{t}\right)-\frac{\mathrm{e}^{-\xi \omega_{0} \mathrm{t}} \cdot \xi \cdot \sin \left(\omega_{0} \cdot \sqrt{1-\xi^{2}} \cdot \mathrm{t}\right)}{\sqrt{1-\xi^{2}}}
$$

The coordinates of two points of the above response provide the values of $\omega_{0}$ and $\xi$. The parameter located outside the tolerance domains will be the fault cause. In Figure 4, form plots of the step response are drown for different values of $\omega_{0}$ and $\xi$. As shown in Table 3, only the green plot is not fault as confirmed by Figure 5 where the plots are superposed to the safe functioning domain.

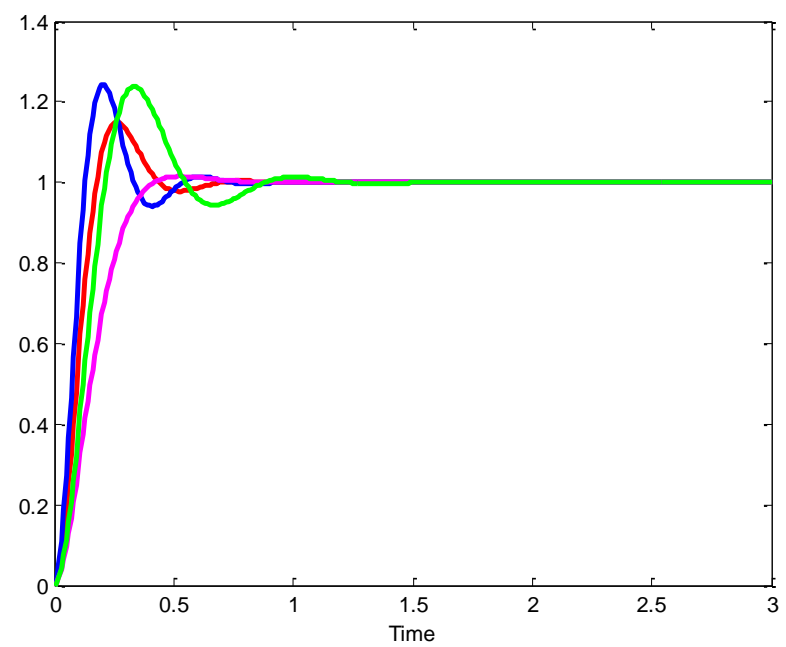

Figure 4. Step response of the second order system for different values of $\omega_{0}$ and $\xi$

Table 2

\begin{tabular}{|c|c|c|l|}
\hline Curve color & Chosen coordinates & Values of $\boldsymbol{\omega}_{\mathbf{0}}$ and $\boldsymbol{\xi}$ & Fault cause \\
\hline \multirow{2}{*}{ Green } & $(0.936 ; 1.767)$ & $\omega_{0}=10.321$ & \\
\cline { 2 - 4 } & $(1.218 ; 1.30)$ & $\xi=0.417$ & no fault \\
\hline
\end{tabular}




\begin{tabular}{|c|c|c|c|}
\hline \multirow{2}{*}{ Blue } & $(0.927 ; 1.39)$ & $\omega_{0}=16.899$ & \multirow{2}{*}{$\omega_{0}$} \\
\cline { 2 - 3 } & $(1.236 ; 1.23)$ & $\xi=0.411$ & \\
\hline \multirow{2}{*}{ Red } & $(0.963 ; 1.5)$ & $\omega_{0}=14.012$ & \multirow{2}{*}{$\omega_{0}$ and $\xi$} \\
\cline { 2 - 3 } & $(1.145 ; 1.27)$ & $\xi=0.521$ & \\
\hline \multirow{2}{*}{ Violet } & $(0.8 ; 1.25)$ & $\omega_{0}=9.921$ & \multirow{2}{*}{$\xi$} \\
\cline { 2 - 3 } & $(1.009 ; 1.53)$ & $\xi=0.797$ & \\
\hline
\end{tabular}

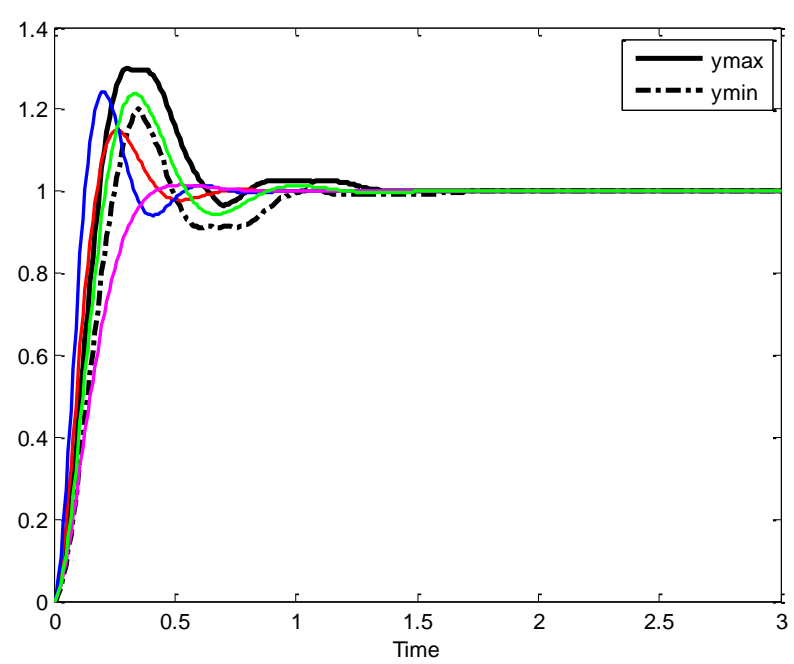

Figure 5. Superposition of step responses with the safe functioning domain

\section{Remark}

This graphical approach may suffer from some results uncertainty, due the risk of inaccuracy in determining the points coordinates. Moreover even if the results are convincing for the second and the third order, this assumption can't be assumed for higher order because of the equation complexity.

\section{Conclusion}

In this paper we have used the sensitivity notion for the fault detection and localization in the second order and the third order linear system given by their transfer functions. Although its sufficiency, this approach raises the deficiency of affecting both the system and the sensor. Therefore to insure that the fault cause result from system parameters we have guarantee the safe functioning of the sensor. 


\section{References}

[1] H. Bedoui, N. Bouguila, K. B. Othman and M. Hassani, "Modeling of the injection and potential decay of a dielectric placed in an environment with high voltage", presented at the International Conference on Control, Decision and Information Technologies CoDIT, Hammamet Tunisia, (2013).

[2] H. Bedoui, "Dynamique des charges dans les isolants portés à haute tension", Editions universitaires europeennes, (2013).

[3] M. Desai, J. Deckert, J. Deyst, A. Willsky and E. Chow, "Dual redundant sensor FDI techniques applied to the NASA F8C DFBW aircraft", (1976).

[4] I. M. Horowitz, "Active network synthesis", in IRE Convention Record, Part, (1956), pp. 38.

[5] A. Akhenak, "Conception d'observateurs non linéaires par approche multi-modèle: application au diagnostic", Doctorat de l'Institut National Polytechnique de Lorraine, vol. 16, (2004).

[6] C. Johnson, "On observers for systems with unknown and inaccessible inputs", International Journal of Control, vol. 21, (1975), pp. 825-831.

[7] L. Thiaw, K. Madani, R. R. Malti and G. Sow, "Implementation of recurrent multi-models for system identification", in Fourth International Conference on Informatics in Control, Automation and Robotics, (2007), pp. 314-321.

[8] M. Chadli, A. Akhenak, J. Ragot and D. Maquin, "State and unknown input estimation for discrete time multiple model", Journal of the Franklin Institute, vol. 346, (2009), pp. 593-610.

[9] G. Zwingelstein, "Diagnostic des défaillances: théorie et pratique pour les systèmes industriels", Hermès, (1995).

[10] S. Boyd, L. El-Ghaoui, E. Feron, V. Balakrishnan and E. Yaz, "Linear matrix inequalities in system and control theory", Proceedings of the IEEE, vol. 85, (1997), pp. 698-699.

[11] M. Darouach, M. Zasadzinski and S. J. Xu, "Full-order observers for linear systems with unknown inputs", Automatic Control, IEEE Transactions on, vol. 39, (1994), pp. 606-609.

[12] L. Pau, "Diagnostic des pannes dans les systemes", Cepadues-Editions, Toulouse, (1975), pp. 72-22.

[13] C. Edwards and C. P. Tan, "A comparison of sliding mode and unknown input observers for fault reconstruction", European Journal of control, vol. 12, (2006), pp. 245-260.

[14] Y. Guan and M. Saif, "A novel approach to the design of unknown input observers", Automatic Control, IEEE Transactions on, vol. 36, (1991), pp. 632-635.

\section{Authors}

Hassene Bedoui was born in Tunisia in 1979. He obtained the master degree in automatic and industrial maintenance from the "Ecole Nationale d'Ingenieurs de Monastir" in 2007. He is currently preparing the $\mathrm{Ph}$. $\mathrm{D}$ degree in automatic and diagnosis within the framework of LARATSI-ENIM. His research is related to state and faults estimation for uncertain takagisugeno fuzzy systems.

Nasereddine Bouguila was born in Tunisia in 1961. He obtained Ph. D degree from the "Université Paris 6 - Pierre et Marie Curie" in 1990 and HDR from the "Ecole Nationale d'Ingenieurs de Monastir" in 2013. He is currently professor at "Ecole Nationale d'Ingenieurs de Monastir".

Kamel Ben Othman was born in Tunisia in 1958. He obtained the engineer degree in mechanical and energetic engineering from the "universite de Valencienne - France" in 1981 and obtain $\mathrm{Ph}$. D degree in automatic and signal processing from the "universite de Valencienne - France" in 1984 and HDR from the "Ecole Nationale d'Ingenieurs de Tunis" in 2008. He is currently professor at ISSTE Gafsa. 
International Journal of Control and Automation Vol.7, No.5 (2014) 